\title{
Exposing kaolinite active sites and evaluating their activity in dimethyl ether preparation from methanol
}

\begin{abstract}
This study is an attempt to exposing kaolinite active sites and find out its catalytic efficiency in methanol dehydration to dimethyl ether (DME) using urea as a green chemical compound. The reaction was carried out at different reaction temperatures, different contact times and under atmospheric pressure. Natural kaolinite $(\mathrm{KN})$ was treated with urea by two techniques which followed by boiling (U-K-B) or ultrasonication (U-K-US) in deionized water. These samples were characterized by X-ray diffraction (XRD), Fourier transform infrared spectroscopy (FTIR), scanning and transmission electron microscopy (SEM and TEM), thermo-gravimetric analysis (TGA) and acid-base titration. XRD revealed that urea was intercalated in-between kaolinite layers and intercalation ratio is computed. FTIR and TGA confirmed that urea was eliminated from U-K-B but $3.3 \%$ still intercalated in U-K-US sample. TEM showed three steps for folding (nanoscrolling) of kaolinite monolayers. Although acid-base titration is a traditional method for evaluating Brønsted surface acidity but it is confirmed that U-K-B sample have higher acidity than U-K-US sample. So, ureakaolinite complex which treated by boiling in water (U-K-B) have better performance in DME preparation with conversion of $87.5 \%$ and DME yield of $87.0 \%$ relative to sonicated sample (U-K-US).
\end{abstract}

Keywords: nanoscroll, kaolinite, characterization, dimethyl ether preparation
Volume 3 Issue I - 2018

\author{
Sanaa M Solyman \\ Egyptian Petroleum Research Institute, AL-Ghad International \\ College for Applied Medical Sciences, Kingdom of Saudi Arabia \\ Correspondence: Sanaa M Solyman, Egyptian Petroleum \\ Research Institute,AL-Ghad International College for Applied \\ Medical Sciences, Kingdom of Saudi Arabia, \\ Emailsanaa8763@hotmail.com
}

Received: January 28, 2018 | Published: February 20, 2018

\section{Introduction}

Dimethyl ether (DME) has commercial importance which is increased considerably in recent years. Diesel exhausts had been linked to cancer in a recent World Health Organization report, ${ }^{1}$ thus clean alternatives are desired. ${ }^{2}$ DME is extremely clean-burning and does not form peroxides as do higher ethers, and renewable and oxygenated alternative fuel for diesel engines. ${ }^{3}$ In addition DME is being considered as IGCC power generation, ${ }^{4}$ home fuel applications, and intermediate in petrochemical industry. Methanol dehydration to dimethyl ether over solid acid catalysts was first reported by Mobil in 1965. It is generally established that acid catalysts are the best materials for the dehydration of methanol to dimethyl ether and that either Brønsted or Lewis acids are capable for performing this reaction. However, most of these solid-acid catalysts produce undesirable side products, such as hydrocarbons and coke due to strong acid sites and higher dehydration temperature. ${ }^{5,6}$ Thus, extensive research has been focused on finding better catalysts which have higher selectivity for DME formation and fewer tendencies to generate hydrocarbons and coke. ${ }^{2}$ Several solid-acid catalysts such as HZSM-5, H-beta, alumina, and SAPOs were reported for methanol dehydration in a temperature rang of $250-400^{\circ} \mathrm{C} .{ }^{7,8}$ Solyman et al. ${ }^{9}$ modified H-Beta and $\mathrm{H}$-Mordenite using ultrasonication technique, which resulted in complete conversion of methanol with complete selectivity to DME at 125,150 , and $175^{\circ} \mathrm{C}$ under different contact times.

Kaolinite is a commercial solid acid catalyst which deactivates rapidly and has a tendency to generate hydrocarbon and coke, due to strong acid sites. ${ }^{10}$ If kaolinite is treated to be having benefit acidity for DME preparation, this will be a very important result. So, the performance of modified kaolinite in the present reaction had been previously studied via intercalation with alumina, ${ }^{11}$ chemical treatment by $\mathrm{H}_{2} \mathrm{O}_{2}$, and mechanochemical treatment by ball milling with and without $\mathrm{CaSO}_{4} \cdot{ }^{12}$

Both kaolinite and urea are cheap, commercial, and save chemical compounds. Thus, the modification of kaolinite with urea to be used in the preparation of a clean fuel and fine chemical such as DME is a goal that has an economic benefit. So in the present study, the deep active sites of kaolinite were exposed through exfoliation and delamination to monolayers and nanoscroll, using urea via two methods. The effect of these modifications on kaolinite crystal structure was studied using XRD, FTIR, SEM, TEM, TGA, and acid-base titration techniques. Also, the catalytic activity of these modified kaolinite samples was evaluated in DME preparation through methanol dehydration reaction and correlated with their characterization results.

\section{Experimental}

\section{Kaolinite modification with urea}

Exposing of kaolinite active sites was carried out through its exfoliation and delamination using urea by dynamic and static intercalation techniques as described in previous publication. ${ }^{13}$ The dynamic intercalation was accomplished via grinding of $10 \mathrm{~g}$ of natural kaolinite (KN) with $2.5 \mathrm{~g}$ of urea $(20 \%)$ for $1 \mathrm{~h}$. The produced sample was treated via static intercalation technique by placing it in closed vessel and heating in a furnace at $95^{\circ} \mathrm{C}$ for $48 \mathrm{~h}$, then was cooled and grinded. The resulted urea-kaolinite complex is denoted as (U-K). Urea-kaolinite intercalation was promoted by dividing this complex into two parts, the first part ultrasonicated in deionized water with heating to $\sim 60^{\circ} \mathrm{C}$ (heat resulted from sonication) for $1 \mathrm{~h}$, and the second part was boiled in deionized water for $1 \mathrm{~h}$. The two samples were washed and separated by centrifugation, then dried at $45^{\circ} \mathrm{C}$ for $48 \mathrm{~h}$, and denoted as U-K-US and U-K-B, respectively. 
Ultrasonication was carried out with amplitude 60 , cycle $=1$, and using a commercial sonicator VCX-750 (Sonics and materials, Inc) equipped with a titanium probe (diameter $13 \mathrm{~mm}$ ), frequency of 20 $\mathrm{KHz}$. These two catalyst samples were activated at $300^{\circ} \mathrm{C}$ in nitrogen atmosphere before the dehydration reaction.

\section{Catalyst characterization}

The two catalyst samples, U-K-B and U-K-US were characterized by XRD analysis using Bruker axs-D8 Advance $\mathrm{CuK} \alpha$ target with secondary monochromator. Chemical structural features were revealed through FTIR measurements using Nicolet IS-10 FTIR over the wave number $4000-400 \mathrm{~cm}^{-1}$. A JEOL JSM-5300 instrument working at $30 \mathrm{kV}$ (SEM) was used for taking the scanning electron microscopy images. The instrument JEOL 2011 (Japan) electron microscope at $200 \mathrm{k} \mathrm{V}$ (TEM) was used for taking the transmission electron microscopy images. Thermo-gravimetric analysis (TGA) was carried out using the instrument SDT Q600 V20.5 Build15. Measurement of Brønsted surface acidity of the treated kaolinite samples was carried out by base exchange followed by acid titration using standardized $0.1 \mathrm{M} \mathrm{HCl}$ and $0.1 \mathrm{M} \mathrm{KOH}$ as follow: ${ }^{14} 0.5 \mathrm{~g}$ of the solid catalyst was dispersed in $120 \mathrm{ml} \mathrm{KOH}$ and agitated for $0.5 \mathrm{~min}$, then settled for $1 \mathrm{~min} ; 10 \mathrm{ml}$ from this suspension was withdrawn and filtered. This step was repeated and $10 \mathrm{ml}$ was withdrawn after $1.5,3.0,4.5,6.0$, $7.5,9.0,10.5,12.0,15.5,30.0$, and $720 \mathrm{~min} ; 1 \mathrm{~min}$ for sedimentation was allowed before each withdrawal which followed by filtration. 5 $\mathrm{ml}$ of the filtrate was titrated with $0.1 \mathrm{M} \mathrm{HCL}$ using phenolphthalein indicator. Brønsted surface acidity was estimated as milliequivalent for $1 \mathrm{~g}$ catalyst $(\mathrm{meq} / \mathrm{g})$.

\section{Dimethyl ether preparation}

The catalytic activity of U-K-B and U-K-US samples in vapor phase methanol dehydration to DME was evaluated. The reaction was carried out in a conventional flow type reactor ${ }^{12}$ at a reaction temperature ranged from 200 to $450^{\circ} \mathrm{C}$; contact times of 15,30 and $45 \mathrm{~min}$, and a catalyst weight of $2.5 \mathrm{~g}$. The reaction products were analyzed using gas liquid chromatography (Hewlett Packard -5890) equipped with flame ionization detector and connected with Carbowax backed column.

\section{Results and discussion}

\section{XRD analysis of parent and treated kaolinite}

Figure 1 show XRD patterns of U-K-B, U-K-US and natural kaolinite $(\mathrm{KN})$ for comparison. The diffraction pattern of U-K-B sample shows a pronounced reduction in the intensity of all diffraction peaks which accompanied with broadening in 001 and 002 basal planes relative to its parent $\mathrm{KN}$, which had been previously published. ${ }^{11}$ This indicates that urea is intercalated with kaolinite and leads to the breakdown of kaolinite crystals along the basal planes. Also, there are two broad peaks for 001 plane appear at $2 \theta^{\circ}=12.34^{\circ}$ and $10.55^{\circ}$ corresponding to d-spacing of $7.17 \AA$ and $8.38 \AA$. These results confirm urea intercalation in-between kaolinite layers. This intercalation may be accompanied with exfoliation/delamination which result in a new phase $(\mathrm{H})$ that was confirmed by Valášková et al. ${ }^{15}$ The extent of ureakaolinite intercalation was monitored using the intercalation ratio (IR) according to Wiewiora and Brindley equation. ${ }^{16}$ It is found that the IR ratio is $43 \%$ with $d$-spacing $=8.38 \AA$ in sample U-K-B indicating incomplete exfoliation/delamination of kaolinite in U-K-B sample. ${ }^{17,18}$ On the other hand, the intensity of some diffraction peaks in U-K-US pattern is nearly similar to that of $\mathrm{KN}$ but more intense and sharp relative to U-K-B peaks. This may indicate that the sample U-K-US is more crystalline than U-K-B sample. Also, 001 plane have two peaks which appear at $2 \theta^{\circ}=12.32^{\circ}$ (broad) and $8.27^{\circ}$ (sharp), corresponding to d-spacing $=7.18 \AA$ and $10.68 \AA$, respectively. This is confirmed by computing the intercalation ratio (IR) which is increased to $71 \%$ due to ultrasonication in U-K-US sample relative to U-K-B (43\%). The abovementioned results and the comparison between d-spacing of 001 plane for $\mathrm{KN}$ against low angle 001 planes for U-K-B and U-KUS (which are $7.13,8.38$ and $10.68 \AA$ respectively) mostly indicates the presence of nanoscroll in modified samples, more exfoliating and delaminating of kaolinite crystals in U-K-US relative to U-K-B and formation of a new phase H. ${ }^{12,17,18}$

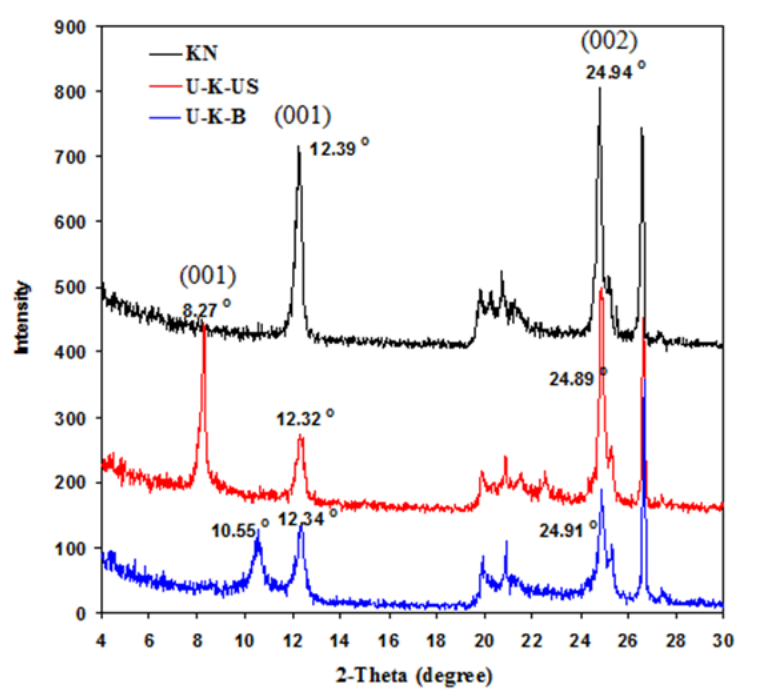

Figure I X-ray diffraction patterns of natural kaolinite (KN), sonicated (U-KUS) and boiled (U-K-B) samples.

\section{FTIR- Spectroscopic analysis}

FTIR spectroscopic analysis for both treated samples U-K-B and U-K-US are shown in Figure 2. This figure may indicate the presence of the inner-surface hydroxyl vibrations in which hydrogen is oriented towards the interlayer (at $\sim 3697$ and $3653 \mathrm{~cm}^{-1}$ ), and the hydrogen of the inner hydroxyls which oriented towards the vacant sites (at $\sim 3620$ and $\left.912 \mathrm{~cm}^{-1}\right) .{ }^{15}$ The intensity of these bands and the framework bands (from 400 to $1100 \mathrm{~cm}^{-1}$ ) is similar to those of parent kaolinite (inset in Figure 2) in U-K-B spectrum, but is increased in U-K-US spectrum. This finding may indicate more terminal $\mathrm{AlOH}$ and $\mathrm{SiOH}$ due to ultrasonication..$^{12}$ Also, there are new bands appear in the spectrum of U-K-US sample as follow: strong band at $3503 \mathrm{~cm}^{-1}$ due to hydrogen bonding between $\mathrm{NH}_{2}$ and siloxane group (O-Si-O), ${ }^{15,18}$ two weak bands at 3417 and $3394 \mathrm{~cm}^{-1}$ due to symmetric and asymmetric stretching vibration of $\mathrm{NH}_{2}$ groups, which may interact with the oxygen of $\mathrm{Si}_{2} \mathrm{O}_{5}$ layer and the weaken hydrogen bonding between kaolinite layers, ${ }^{15} \mathrm{C}=\mathrm{O}$ stretching bands at 1675,1622 , and $1589 \mathrm{~cm}^{-1}$ and vibration band at $1477 \mathrm{~cm}^{-1}$ due to $\mathrm{HNC}$ deformation of urea molecules. ${ }^{19}$ These results mostly indicate the presence of urea which is intercalated with the tetrahedral sheet of kaolinite crystal. On the other hand, U-K-B have small and weak band at $3541 \mathrm{~cm}^{-1}$ and other weak and broad band at $1657 \mathrm{~cm}^{-1}$. This may be attributed to $\mathrm{O}-\mathrm{H}$ stretching and binding vibrations of residual water which causes an increase of the interlayer space, even after drying for sample U-K-B. ${ }^{15}$ These results indicate that urea molecules may be not present in U-K-B sample. 


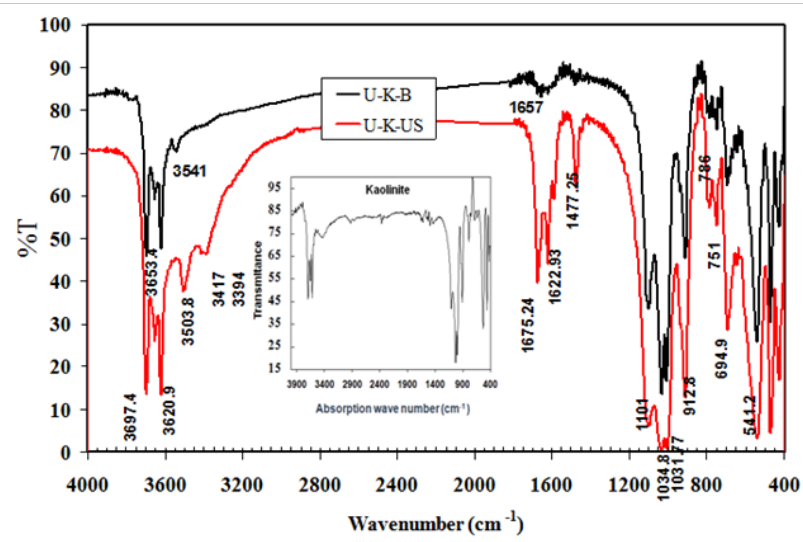

Figure 2 FTIR spectroscopic analysis of treated kaolinite samples (U-K-US) and $(\mathrm{U}-\mathrm{K}-\mathrm{B})$. The inset spectrum is for natural kaolinite $(\mathrm{KN})$.

\section{Scanning Electron Microscopy (SEM) of treated samples}

Figure 3 shows the morphology of treated urea-kaolinite complex samples by boiling (U-K-B) and ultrasonication in water (U-K-US). The figure shows the presence of very thin irregular kaolinite plates, scroll and curved plates in both samples but the ultrasonicated sample have more homogeneous morphology. The scrolling of kaolinite plates is not complete with all sheets mostly because of the small diameter of urea molecules and its low concentration in U-K complex $(20 \% \mathrm{wt}){ }^{20}$

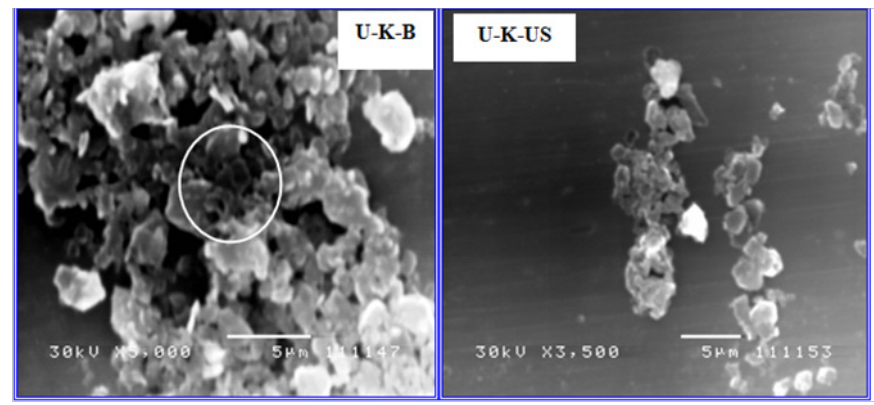

Figure 3 SEM micrographs for treated U-K complex samples U-K-B and U-K-US.

\section{Transmission Electron Microscopy (TEM) of treated samples}

Figure 4 shows different micrographs for sonicated sample U-KUS. Figure 4A shows intercalated hexagonal kaolinite monolayers with different d-spacings, which have well-defined edges and corners. ${ }^{13}$ This indicates high degree of kaolinite crystallinity which is consistent with the XRD data. There are dark spots which may be urea or its trapped decomposition products such as $\mathrm{NH}_{3}, \mathrm{HCN}$ and $\mathrm{CO}_{2}$ as will be shown in the following discussion parts (Figure 4B). Also, nanoscrolls with different sizes and tubular form and monolayers folded surrounding each other are clear in Figure 4(C,D) ${ }^{21}$

Figure 5 shows TEM micrographs which indicate three steps of scrolling in U-K-B sample. The three micrographs show separated kaolinite monolayers due to their interaction with urea and then appear as a curve like tree leaf then scrolled as appeared in Figure 5A5C. ${ }^{13}$ TEM images confirm partial exfoliation/delamination followed by scrolling and U-K-B sample is pure relative to U-K-US sample.
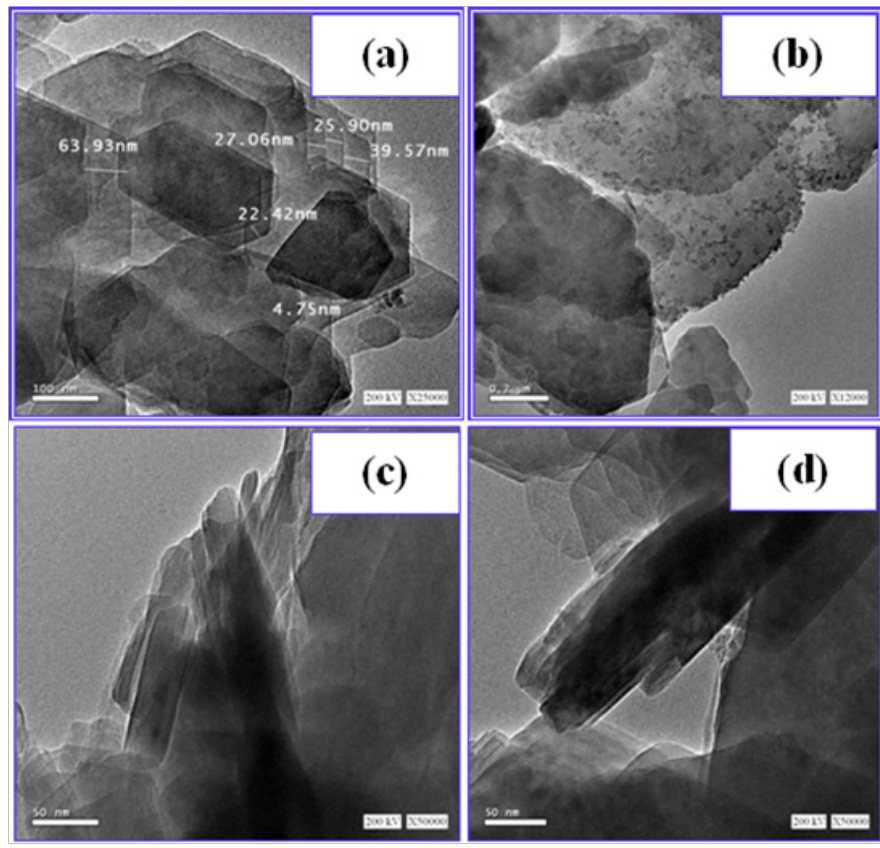

Figure 4 Different TEM images for sonicated sample (U-K-US).

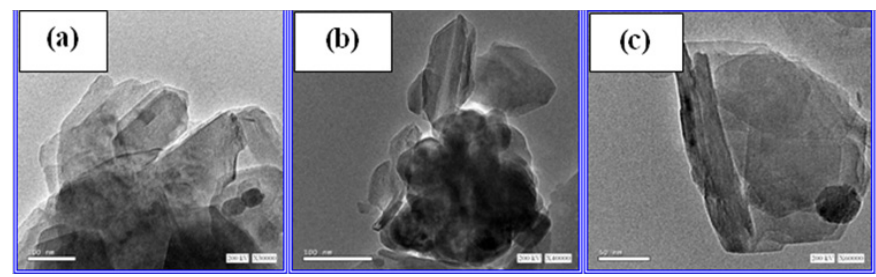

Figure 5 Different TEM images for boiled sample (U-K-B).

Thermo-gravimetric analysis (TGA) of treated samples

Figure 6 shows the Thermo-gravimetric analysis of U-K-B and U-K-US samples from 50 to $650^{\circ} \mathrm{C}$. The total weight losing of U-K-B sample is $14.8 \%$ in two steps. The first step starts from $50^{\circ} \mathrm{C}$ to $418^{\circ} \mathrm{C}$, due to the libration of physisorbed water and water of kaolinite crystallinity. The weight losing of this step is $3.5 \%$. The second losing step starts from $418^{\circ} \mathrm{C}$ to $650^{\circ} \mathrm{C}$ due to the thermal dehydroxylation process. ${ }^{11}$ The weight loss of this step is $10.8 \%$. On the other hand, the thermogram of second sample U-K-US shows three steps for weight losing, where the total mass losing value is $17.0 \%$. The first mass losing step (5.1\%) starts from $50^{\circ} \mathrm{C}$ to $221^{\circ} \mathrm{C}$ due to: 1$)$ the libration of physisorbed water with weight loss of $0.9 \%$ from 50 to $133^{\circ} \mathrm{C}, 2$ ) urea melting at $133^{\circ} \mathrm{C}$ up to $221^{\circ} \mathrm{C}$ and thus its decomposition in this range with weight loss of $3.3 \%$ and 3 ) libration of physisorbed water and water of crystallinity with weight losing of $(\sim 0.9 \%)$. The second mass losing $1.7 \%$ starts from $221^{\circ} \mathrm{C}$ to $418^{\circ} \mathrm{C}$, which is the same value of the temperature range from the thermogram of U-K-B. These observations confirm that this weight losing may be attributed to the libration of physisorbed water and water of crystallinity, and that urea may react with the librated water and decomposes completely up to $221^{\circ} \mathrm{C}$ according to the following equation (eq. 1):

$\left(\mathrm{NH}_{2}\right)_{2} \mathrm{CO}+\mathrm{H}_{2} \mathrm{O} \rightarrow 2 \mathrm{NH}_{3}+\mathrm{CO}_{2}$ 


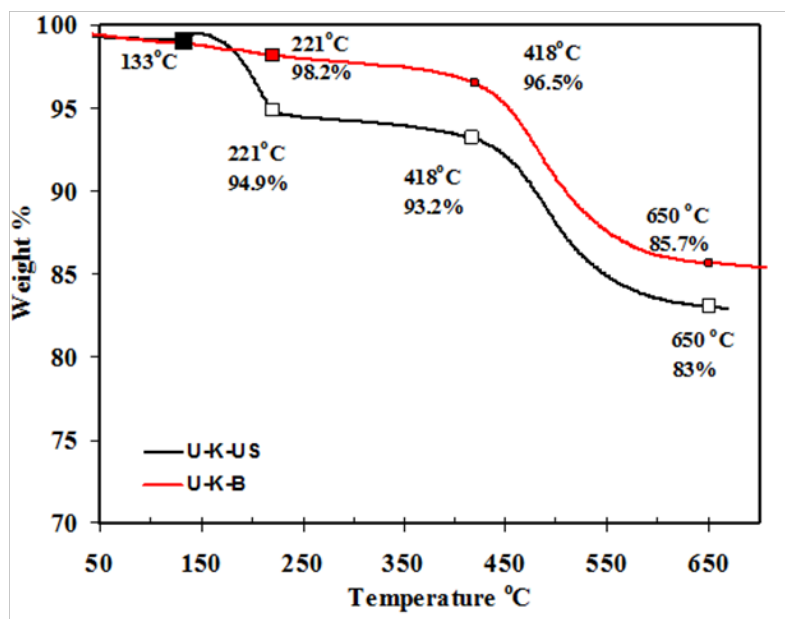

Figure 6 Thermo-gravimetric analysis of treated U-K complex samples U-K-B and U-K-US.

The fourth mass losing step starts from $418^{\circ} \mathrm{C}$ to $650^{\circ} \mathrm{C}$ with weight loss of $10.2 \%$ due to thermal dehydroxylation process such as in U-K-B thermograme. These results confirm the phenomenon that urea removed completely due to boiling in deionized water. On the other hand, urea weight $\%$ in U-K complex is $20 \%$. So, it can be computed that $16.7 \%$ urea is removed during ultrasonication in deionized water at $\sim 60^{\circ} \mathrm{C}$ and $3.3 \%$ still interacts with kaolinite layers in U-K-US sample. These results coincide with FTIR explanation and TEM images.

\section{Brønsted surface acidity of the treated kaolinite samples}

Figure 7 shows the estimated Brønsted surface acidity of treated kaolinite samples U-K-B and U-K-US by shaking with KOH solution followed by titration with $\mathrm{HCl}$ solution which results in three observations.

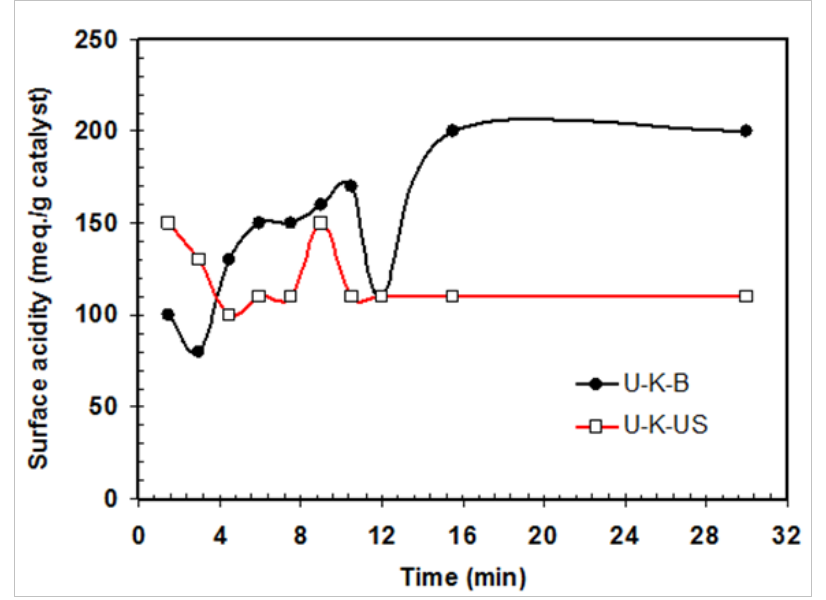

Figure 7 Bronsted surface acidity of U-K-B and U-K-US samples by acid-base titration.

The first observation: the initial surface acidity values of U-K-B and U-K-US samples are 100 and 150 meq. $\mathrm{g}^{-1}$, respectively after $1.5 \mathrm{~min}$. Brønsted surface acidity of kaolinite mostly promote the formation of hydrogen cyanide $(\mathrm{HCN})$ which trapped on kaolinite surface in U-KUS sample. HCN is slightly acidic and may be responsible for the high initial acidity (150 meq./g) at $1.5 \mathrm{~min}$.
The second observation: the surface acidity values change between decent and ascent after different time intervals of shaking and then are stabilized. This change may be due to interacted $\mathrm{NH}_{3}$ and $\mathrm{CO}_{2}$ molecules on acidic and basic sites, respectively of kaolinite surface. Literatures have been indicated that potassium hydroxide and other basic hydroxides can be used as adsorbents for $\mathrm{CO}_{2}$ in purification process for clay. ${ }^{22,23}$ So, a volume of $\mathrm{KOH}$ solution may be consumed by $\mathrm{CO}_{2}$ molecules according to the following equation and results in a change in the calculated acidity value:

$$
2 \mathrm{KOH}+\mathrm{CO}_{2} \rightarrow \mathrm{K}_{2} \mathrm{CO}_{3}+\mathrm{H}_{2} \mathrm{O}
$$

The third observation: the final surface acidity values of U-K-B and U-K-US samples are 200 and 110 meq. $\mathrm{g}^{-1}$ after 15.5 and 10.5 min, respectively (see Figure 7) and still stable up to $720 \mathrm{~min}$. This result indicates that sonicated sample (U-K-US) mostly suffers dealumination which results in a decrease in its Brønsted surface acidity. ${ }^{14}$ It is concluded that the traditional acid -base titration technique give an important idea that U-K-B sample have higher Brønsted acidity relative to U-K-US sample.

\section{The mechanism of kaolinite scrolling through urea- kaolinite intercalation}

Figure 8 shows the exfoliation and delamination mechanism of kaolinite layers to separated and folded monolayer through its intercalation with urea as follow: urea molecules are diffused and intercalated in-between kaolinite layers by dynamic and static process due to grinding and heating in a furnace at $95^{\circ} \mathrm{C}$, respectively producing urea-kaolinite complex. Part of this complex is treated with boiling water and the other part is treated by sonication in hot water. ${ }^{20}$ These treatments result in increasing the $\mathrm{d}$-spacing values due to several factors:

i. Water may act as a modifier for kaolinite surface by swelling, converting agglomerated urea particles to singular molecules and thus promotes its diffusion and intercalation in-between kaolinite layers.

ii. Urea promotes water ionization and thus increases the solution $\mathrm{pH}$, this may produce a repulsion force between kaolinite layers, so increases the $\mathrm{d}$-spacing value, ${ }^{22}$

iii. Urea is intercalated with the oxygen of silicate tetrahedral sheet (001 plane) with hydrogen bonding and thus weaken the hydrogen bonding between two adjacent layers so, increases the d-spacing value

iv. Due to heating effect, urea decomposition to carbon dioxide and ammonia can be activated according to Yan et al. ${ }^{13}$ which may form ammonium hydroxide that may increase the repulsion force between kaolinite layers, finally.

v. Ultrasonication in U-K-US sample has a mechanical stress on the attracting forces between kaolinite layers; resulting in better swelling of kaolinite with water, accelerates the movement and the dispersion of single urea molecules in-between kaolinite layers; and thus higher intercalation ratio (71\%), more exfoliation/delamination, and more scrolling relative to the other sample (U-K-B) which have $43 \%$ intercalation ratio. Mostly, the breakdown of hydrogen bonding between kaolinite layers due to its intercalation with urea is accompanied by its scrolling. ${ }^{13,23,24}$ Urea decomposition may be catalyzed by kaolinite active sites producing $\mathrm{HCN}$ in case of U-K-US. ${ }^{25}$ 


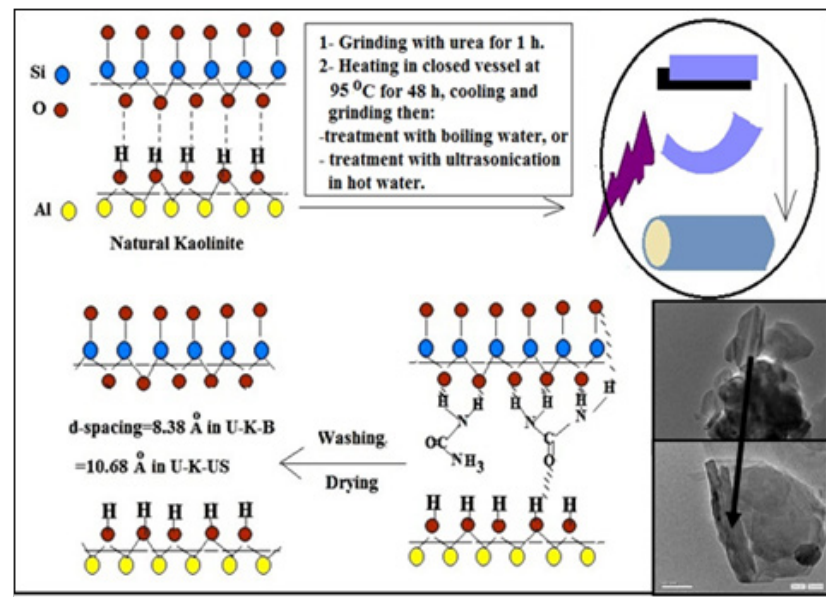

Figure 8 Kaolinite treatment with urea.

\section{The evaluation of modified kaolinite samples in dimethyl ether preparation}

Exfoliation/Delamination of kaolinite particles exposes some active sites which mostly improve the catalytic activity of kaolinite. So, the performance of treated kaolinite samples has been evaluated by studying the conversion percent of methanol by its dehydration (conv.\%) and the yield percent of dimethyl ether (Y\%) using both treated samples, U-K-B in Figure 9 and U-K-US in Figure 10. The reaction temperature is ranged from 200 to $450^{\circ} \mathrm{C}$ at different contact times 15,30 , and 45 min.

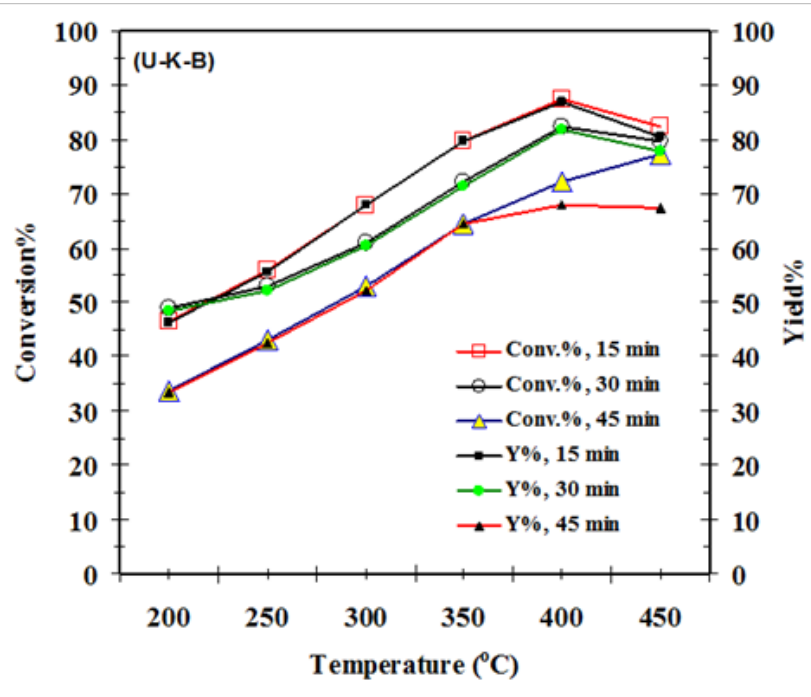

Figure 9 The effect of reaction temperatures on the conversion\% of methanol and the yield\% of dimethyl ether using U-K-B sample at different contact times.

Generally, the two figures indicate that U-K-B is more active than U-K-US. This observation can be attributed to the final Brønsted surface acidity which is higher for U-K-B. The maximum conversion and yield $\%$ are 87.5 and 86.8 respectively at $400^{\circ} \mathrm{C}$ with contact time 15 min using U-K-B as shown in Figure 9, while by using U-KUS sample the maximum conv. $\%$ decreases to 45 and the maximum $\mathrm{Y} \%$ decreases to 43.2 at $400^{\circ} \mathrm{C}$ and contact time of $30 \mathrm{~min}$ (Figure 10 ). By using U-K-B catalyst, the conv.\% and the Y\% at all reaction temperatures are increased relative to parent kaolinite $(\mathrm{KN})$, as previously published. ${ }^{12}$ This means that the modification in sample U-K-B has been created or exposed moderate active sites (bridged silanol groups) which have better activity in methanol dehydration and selectivity to DME at low reaction temperatures. ${ }^{9,12}$ Also, more concentration of terminal silanol groups (strong active sites) has been created or exposed because the performance at high reaction temperatures i. e, the conv. $\%$ and the $\mathrm{Y} \%$ are increased up to $400^{\circ} \mathrm{C}$. Above 350 and $400^{\circ} \mathrm{C}$ with different contact times, the conv. $\%$ and the $\mathrm{Y} \%$ are decreased mostly because of these strong active sites which promote olefin formation and coking (decomposition of methanol and olefins producing carbon) thus deactivate the catalyst at elevated temperatures and higher contact time $(45 \mathrm{~min})$ as shown in Figure $9.9,12$

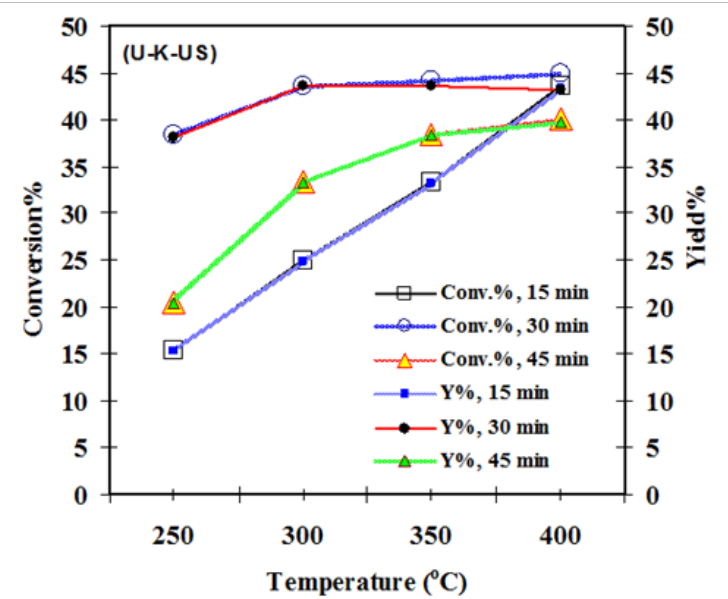

Figure 10 The effect of reaction temperature on the conversion\% of methanol and the yield\% of dimethyl ether using U-K-US sample at different contact times.

On the other hand, U-K-US sample has urea molecules which still present and intercalate with some kaolinite layers. Catalyst characterization documents that urea molecules are melted and mostly decomposed thermally to $\mathrm{NH}_{3}$ and $\mathrm{CO}_{2}$ in the reaction temperature range. These gases must be escaped at all reaction temperatures, so more active sites must be exposed which result higher activity relative to U-K-B sample. Figure 10 indicates the opposite, because the conv. $\%$ and the $\mathrm{Y} \%$ are decreased with large extent relative to the results in Figure 9 using U-K-B catalyst. This means that the decline in the performance of U-K-US sample may be resulted due to some other reasons. Firstly; the presence of urea, ammonia, and $\mathrm{CO}_{2}$ mostly overcrowding the active sites. Secondly; thermal-catalytic oxidation of ammonia into nitrogen oxide and $\mathrm{CO}_{2}$ gases may be proceeds by kaolinite strong active sites during the reaction and also thermalcatalytic reduction of carbon dioxide into carbon. This carbon mostly poisoning the kaolinite active sites in U-K-US sample ( $\mathrm{IC}=71 \%)$ with higher extent relative to U-K-B sample ( $\mathrm{IC}=43 \%$ ), and thus decreases its catalytic performance. These results are coincided with FTIR results which show a strong band at $912.8 \mathrm{~cm}^{-1}$ due to increasing the terminal silanol groups (strong acid sites).

It can be conclude that the present treatment of kaolinite by boiling $\mathrm{U}-\mathrm{K}$ complex in water has been resulted in a better modification in kaolinite acidity in U-K-B sample with respect to sonicated sample U-K-US. Also, U-K-B catalyst give higher conversion $\%$ for methanol and better yield $\%$ of DME relative to other modification methods by $\mathrm{H}_{2} \mathrm{O}_{2}$, ball milling with and without $\mathrm{CaSO}_{4}$ which published previously. ${ }^{12}$ 


\section{Conclusion}

The present work is a trial to study the performance of kaolinite's exposed active sites in dimethyl ether preparation. This carried out by diffusion and intercalation of urea (U) in-between kaolinite layers $(\mathrm{K})$ through two stages, and then promoted by boiling and by ultrasonication in deionized water to give samples (U-K-B) and (U-K-US). The produced samples are characterized by XRD, FTIR, SEM, TEM, and TGA techniques and acid-base titration. Each sample contains fine hexagonal (planner), curved and folded (nanoscroll) monolayers. Sample U-K-B has higher Brønsted surface acidity, mostly due to creation of moderate acidic sites. So, this sample has good performance and gives methanol conversion of $87.5 \%$ and DME yield of $87.0 \%$. On the other hand, U-K-US sample have created terminal silanol groups which promote cocking. So, the performance of this sample is declined. It is concluded that kaolinite and urea are cheap and save chemical compounds, they can be used to prepare commercial, active, and selective catalyst (nanoscroll kaolinite), but higher concentration of urea can be used to give complete scrolling for kaolinite layers by boiling in water method.

\section{Acknowledgements}

None.

\section{Conflict of interest}

The author declares no conflict of interest.

\section{References}

1. Paddock C. Diesel Exhaust Fumes Cause Cancer. WHO, Medical News Today. 2012

2. Yaripour F, Baghaei F, Schmidt I, et al. Synthesis of dimethyl ether from methanol over aluminium phosphate and silica-titania catalysts. Catal Commun. 2005;6(8):542-549.

3. Semelsberger TA, Borup RL, Greene HL. Dimethyl ether (DME) as an alternative fuel. J Power Sources. 2006;156(2):497-511.

4. Brown DM, Bhatt BL, Hsiung TH, et al. Novel Technology for the Synthesis of Dimethyl Ether from Syn Gas. Catal Today. 1991;8(3):279 304.

5. Xu M, Lunsford JH, Goodman DW, et al. Synthesis of dimethyl ether (DME) from methanol over solid-acid catalysts. Appl Catal A: Gen. 1997;149(2):289-301.

6. Fu Y, Hong T, Chen J, et al. Surface acidity and the dehydration of methanol to dimethyl ether. Thermochim Acta. 2005;434(1-2):22-26.

7. Khandan N, Kazemeini M, Aghaziarati M. Dehydration of Methanol to Dimethyl Ether Employing Modified H-ZSM-5 Catalysts. Iran J Chem Eng. 2009;6(1):3-11.

8. Rostamizadeh N, Sadjadi MS, Sadjadi SAA. Hollow alumina nanospheres as novel catalyst for the conversion of methanol to dimethyl ether. J Particle Sci Techn. 2016;2:15-22.
9. Solyman SM, Aboul-Gheit NAK, Tawfi FM, et al. Performance of ultrasonic - Treated nano-zeolites employed in the preparation of dimethyl ether. Egyptian Journal of Petroleum. 2013;22(1):91-99.

10. Eley DD, Pines H, Weisz PB. Advances in Catalysis. 1978;27:170.

11. Solyman SM, Tawfik FM. A Simple Method for the Preparation of Dimethyl Ether. Egyptian Journal of Petroleum. 2010;19:69-81.

12. Solyman SM, Betiha MA. The performance of chemically and physically modified local kaolinite in methanol dehydration to dimethyl ether. Egyptian Journal of Petroleum. 2014;23(3):247-254.

13. Yan CJ, Chen JY, Zhang CZ, et al. Kaolinite-urea intercalation composites. Am Ceram Soc Bull. 2005;84:9301-9305.

14. Rahman MA, Azad MAK, Ahsan S, et al. Measurement of brønsted acidity of silica-alumina solid catalyst by base exchange method. $J$ Surface Sci Technol. 2006;22(1-2):25-33.

15. Valášková $M$, Rider $M$, Matějk V, et al. Exfoliation/delamination of kaolinite by low-temperature washing of kaolinite-urea intercalates. Appl Clay Sci. 2007;35(1-2):108-118.

16. Wiewiora A, Brindley GW. Potassium acetate intercalation in kaolinites and its removal: effect of material characteristics. In: Heller L, editor. Proceeding of the international clay conference. Jerusalem: Israel University Press; 1969. p.723-733.

17. Letaief S, Detellier C. Clay-polymer nanocomposite material from the delamination of kaolinite in the presence of sodium polyacrylate. Langmuir. 2009;25(18):10975-10979.

18. Macó É, Kristóf J, Horváth E, et al. Kaolinite-urea complexes obtained by mechanochemical and aqueous suspension techniques-A comparative study. J Colloid Interf Sci. 2009;330(2):367-373.

19. Fukamachi CRB, Wypych F, Mangrich AS. Use of $\mathrm{Fe}^{3+}$ ion probe to study the stability of urea-intercalated kaolinite by electron paramagnetic resonance. J Colloid Interf Sci. 2007;313(2):537-541.

20. Liu Q, Li X, Guo P, et al. Formation of Nanoscrolls and Preparation of Kaolinite Intercalation Compound with Alkylamines. J Chin Ceram Soc. 2014;42(8):1064-1069.

21. Letaief S, Leclercq J, Liu Y, et al. Single kaolinite nanometer layers prepared by an in situ polymerization-exfoliation process in the presence of ionic liquids. Langmuir. 2011;27(24):15248-15254.

22. Schütze M, Quadakkers W. Novel Approaches to Improving High Temperature Corrosion Resistance. Elsevier. 2008. 511 p.

23. Yang ZZ, Song QW, He LN. Capture and Utilization of Carbon Dioxide with Polyethylene Glycol. Springer Science and Business Media. Chapter 5: Synthesis of urea derivatives from $\mathrm{CO}_{2}$ and amine. 2012. $66 \mathrm{p}$.

24. Khandan N, Kazemeini M, Aghaziarati M. Dehydration of Methanol to Dimethyl Ether Employing Modified H-ZSM-5 Catalysts. Iran J Chem Eng. 2009;6:3-11.

25. Jones JM, Rollinson AN. Thermogravimetric evolved gas analysis of urea and urea solutions with nickel alumina catalyst. Thermochim Acta. 2013;565:39-45. 